This item was submitted to Loughborough's Research Repository by the author.

Items in Figshare are protected by copyright, with all rights reserved, unless otherwise indicated.

\title{
Optical diagnostics study of air flow and powder fluidisation in Nexthaler (R)- Part I: Studies with lactose placebo formulation
}

PLEASE CITE THE PUBLISHED VERSION

http://dx.doi.org/10.1016/j.ijpharm.2015.10.072

\section{PUBLISHER}

(c) Elsevier

\section{VERSION}

AM (Accepted Manuscript)

\section{PUBLISHER STATEMENT}

This work is made available according to the conditions of the Creative Commons Attribution-NonCommercialNoDerivatives 4.0 International (CC BY-NC-ND 4.0) licence. Full details of this licence are available at: https://creativecommons.org/licenses/by-nc-nd/4.0/

\section{LICENCE}

CC BY-NC-ND 4.0

\section{REPOSITORY RECORD}

Pasquali, I., C. Merusi, G. Brambilla, Edward J. Long, Graham K. Hargrave, and Hendrik K. Versteeg. 2019. "Optical Diagnostics Study of Air Flow and Powder Fluidisation in Nexthaler (r)-part I: Studies with Lactose Placebo Formulation". figshare. https://hdl.handle.net/2134/20347. 
${ }^{2}$ Wolfson School of Mechanical and Manufacturing Engineering, Loughborough University,

$16{ }^{\dagger}$ Corresponding author:

17 Wolfson School of Mechanical and Manufacturing Engineering, Loughborough University, 
21 Effective drug delivery to the lungs by a DPI device requires the air-stream through the device to 22 have sufficient power to aerosolise the powder. Furthermore, sufficient turbulence must be induced, 23 along with particle-wall and particle-particle collisions, in order to de-aggregate small drug particles

24 from large carrier particles. As a result, the emitted and the fine particle doses produced by many 25 commercially available DPI devices tend to be strongly affected by the natural inter-patient 26 variability of the inhaled air flow. The Nexthaler ${ }^{\circledR}$ is a multi-dose breath-actuated dry-powder 27 inhaler with minimum drug delivery-flow rate dependency and incorporating a dose protector. The 28 actuation mechanism of the dose-protector ensures that the dose is only exposed to the inhaled air 29 flow if the flow has sufficient power to cause complete aerosolisation. For this study, a proprietary 30 lactose placebo powder blend was filled into "transparent " Nexthalers $®$ to allow application of high31 speed imaging and particle image velocimetry (PIV) techniques to successfully interrogate and 32 reveal details of the powder entrainment and emission processes coupled with characterisation of 33 the flow environment in the vicinity of the mouthpiece exit.

34 The study showed that fluidisation of the bulk of the powder occurs very quickly ( 20 ms) after withdrawal of the dose protector followed by powder emission from the device within $\sim 50 \mathrm{~ms}$ 36 thereafter. The bulk of the metered placebo dose was emitted within 100-200 ms. The visualisation 37 study also revealed that a very small fraction of powder fines is emitted whilst the dose protector still 38 covers the dosing cup as the flow rate through the device accelerates. The PIV results show that 39 the flow exiting the device is highly turbulent with a rotating flow structure, which forces the particles 40 to follow internal paths having a high probability of wall impacts, suggesting that the flow 41 environment inside the Nexthaler® DPI will be very beneficial for carrier-drug de-aggregation.

43 Keywords: powder fluidization; dry powder inhaler; breath-actuated; optical diagnostics; high-speed 44 imaging; particle image velocimetry; powder emission 


\section{1. Introduction}

48 Dry powder inhalers (DPI) deliver therapeutic agents to the lungs and airways in the form of a 49 powder aerosol. To achieve efficient delivery of these agents to the lungs, perceived wisdom 50 suggests the aerodynamic particle size should range between 1 and $5 \mu \mathrm{m}$ (Laube et al., 2011), 51 although it is arguable that sub-micron particles are also capable of lung deposition and retention, 52 (Acerbi et al., 2007, Church et al., 2010, Kuna et al., 2015). Micronised drug powders in these 53 ranges tend to be very cohesive and, consequently, to ensure flowability during formulation 54 manufacture, device filling, storage and use, drug particles are presented in the form of aggregates 55 of micronized drug particles alone or of drug and coarse lactose carrier particles, (Newman and 56 Busse, 2002).

57 Most of the DPI devices currently on the market are breath-actuated, single-dose or multi-dose DPIs 58 (British National Formulary 68, 2014, EMC, 2015, Physician's Desk Reference, 2015). In these 59 devices, the powder is aerosolised by the flow of air inhaled by the patient, which obviates the need 60 for the patient to coordinate actuation/priming of the device and inhalation. However, as 61 demonstrated in early work (Clark and Hollingsworth, 1993; Hindle and Byron, 1995; de Boer et al., 62 1996), this advantage also has a well-known drawback, for many DPI systems, in that the resultant 63 delivered and fine particle doses vary with the inhalation flow rate, which, in turn, depends on an 64 individual patient's lung function and the device resistance. Staniforth (1995) studied the 65 dependence of the fraction of a powder dose entrained by an air stream in a simple entrainment 66 tube with circular cross-section, on flow velocity and the size of carrier particles. This work showed 67 that partial fluidisation of the powder dose is initiated at lower air velocities, but complete fluidisation 68 requires significantly higher velocities. Furthermore, complete aerosolisation takes place at lower velocities if the particles are larger. Clearly, the patient must be able to inhale with sufficient force to fluidise the powder-dose completely (Laube et al., 2011). Moreover, in-vitro studies have shown 
72 the inhalation flow rate and its temporal profile (Everhard et al., 1997; Hawsksworth et al., 2000;

73 Chavan and Dalby, 2002).

74 Theories of powder fluidisation and de-aggregation (Dunbar et al. 1998, Finlay, 2001) propose that 75 shear fluidisation is responsible for entrainment of particles in the vicinity of a solid wall immersed in 76 a high speed boundary layer. Estimates of the fluid velocity required to initiate particle movement 77 were made on the basis of a balance between aerodynamic lift and drag forces vs. particle weight 78 and adhesion forces. Sweeney and Finlay (2007) gave details of a numerical study of the 79 aerodynamics of a sphere attached to a wall and immersed in a boundary layer under 80 hydrodynamic conditions that are representative of practical DPI flows; this work provided 81 interpolated closed-form relationships for the aerodynamic lift and drag coefficients that are useful 82 for accurate evaluations of the force balance. Voss and Finlay (2002) compared particle de83 aggregation in air flows with independent control of turbulence levels and mechanical impaction 84 conditions in a simplified entrainment tube test rig and a Diskhaler®. Laser-Doppler velocimetry 85 was used to measure turbulent flow velocities inside both systems. Their results showed that 86 turbulence in the air flow is the main variable that affects de-aggregation, an important finding for 87 subsequent device development. In separate work, Wang et al. (2004) studied Ventodisk® powder 88 fluidisation using normally impacting jet flows, as commonly found in commercial DPIs and reported 89 that the jet velocity, the amount of drug formulation loaded and the geometries of the jet and powder 90 dosing cup all affect fluidisation. Powder dispersion and drug de-aggregation were found to be 91 controlled by a combination of the following mechanisms: shear fluidisation, flow turbulence, jet 92 energy as well as particle-wall collisions. Zhou et al. (2010) studied fluidisation of lactose powders 93 with median particle sizes around 4 and $20 \mu \mathrm{m}$, with and without magnesium stearate in a 94 Monodose $\AA$ (RS01 Plastiape) inhaler device. The study highlighted the role of powder bulk characteristics and the potential of powder surface modification to improve aerosol performance, reducing emitted drug dose dependence on the inhalation flow rate and improvement in drug de97 aggregation. The theoretical approach developed by $\mathrm{Xu}$ et al. (2010) for the study of particle 98 fluidisation in turbulent air flows within simplified entrainment tubes enabled predictions of drug fine- 
99 particle fraction in the resultant aerosol cloud. Recent work by Xu and Hickey (2013) confirmed that 100 predictions based on this theory show excellent agreement with the measured trends of fine-particle 101 fractions as a function of air flow rate in commercial DPIs. Despite such investigations, for many 102 widely prescribed products, there remains significant potential for poorly controlled interactions 103 between the powder and inhaled air stream resulting from natural variations in the patterns of 104 patients' inspiration and their different abilities to inhale with sufficient force. These factors can 105 potentially lead to variations in the effectiveness of drug therapy delivered by means of dry-powder 106 inhalers as a consequence of:

107 (i) incomplete powder fluidisation when a patient is unable to inhale sufficiently forcefully.

108 (ii) inconsistency of drug release from carrier vehicles due to variations of the strength of the inhaled air currents.

110 The exact details of the mechanism of powder fluidisation and subsequent drug release into the 111 more complex air stream within commercial DPIs are still not well understood making it difficult to 112 take a fundamental approach to DPI device design, which, consequently, proceeds largely on an 113 empirical basis reliant on extensive use of cascade impaction testing (Friebel et al., 2013). The 114 challenges associated with sensing and measuring the rapid transient motion of dense particle115 laden flows have been insurmountable until fairly recently. However, powerful optical diagnostic 116 techniques are now available for imaging and measurements. One such technique, particle image 117 velocimetry (PIV), was used by Ngoc et al. (2013) to study details of the flow fields and turbulence 118 distribution in a de-agglomeration chamber of an idealised DPI. This yielded a deeper 119 understanding of the flow mechanisms and geometrical factors controlling device performance.

120 In this paper we describe the use of optical diagnostics techniques, comprising high speed imaging 121 coupled with PIV to study powder fluidisation and particle cloud emission from Nexthaler®, a multi122 dose, breath-actuated, dry powder inhaler device approved for the delivery of drug powder 123 formulations for the treatment of Asthma and COPD. 


\section{2. Materials and Methods}

\section{1 "Transparent” Nexthalers}

127 The components of commercial Nexthalers $®$, (Corradi et al., 2014), are machine or hand 128 assembled from filled plastic pieces fabricated on multi-cavity tools. To allow the required internal 129 optical access for this study, "transparent" versions were hand assembled from un-filled pieces, of 130 otherwise identical material composition, fabricated using the identical moulding tools and 131 conditions. For the data presented, two Nexthaler devices were used; one for the imaging testing 132 (refilled as required) and one for the velocity measurements. The device incorporates a dose 133 protector, which covers the metered mass of formulation, (dose), released when the device is 134 primed prior to inhalation. It is designed to retract only when the suction produced by the inspiratory 135 effort of the patient reaches the pre-set "trigger" value. As a consequence, the powder dose can 136 only be exposed to a powerful inhaled air current, thereby ensuring its complete fluidisation and 137 efficient dose emission.

\subsection{Inhalation Powder Formulation}

141 The powder reservoirs of part-assembled devices were hand-filled with $1.5 \mathrm{~g}$ of a proprietary 142 lactose-excipient placebo blend, manufactured at commercial scale (Chiesi Farmaceutici, Parma) 143 and the DPI assembly completed.

$145 \quad 2.3$ Optical Diagnostics Test Rig

\section{$146 \quad 2.3 .1$ Components}

147 The experimental apparatus used for high-speed visualisation and measurement of the particle 148 velocities within and emerging from a "transparent" Nexthaler ${ }^{\circledR}$ comprises a pneumatic suction 149 system equipped with rapid response pressure and flow measurement instrumentation and optical 150 systems. The apparatus, shown schematically in Figures 1-3, was assembled in-house utilising the 151 following components. 
A. Vacuum pump - Edwards Speedivac ED660

154

B. Control valve - Legris Stainless steel ball valve

C. 20 litre steel vacuum vessel

156

D. Sonic Restrictor - made in-house

E. Flow Control Valve - Legris Stainless steel ball valve

F. Rapid Switch Solenoid Controlled Ball Valve - Omal SR15 driven with 6 bar pressure

G. Variable Volume Unit - made in-house

H. Thermal Mass Flow Meter - Sierra 0-200 sl. $\mathrm{min}^{-1}$ Accuracy: $1.0 \%$ of full scale window, internal dimensions of $28 \times 28 \times 60 \mathrm{~mm}$, two variations fitted with a silicone rubber seal where it meets the Nexthaler® Mouthpiece

165 K. Nexthaler® Device

L. Vertical Laser Sheet (see Section 2.3.2)

M. Nikkor $105 \mathrm{~mm}$ macro lens

N. Photron APX RS High-speed camera

O. Front coated mirror $60 \mathrm{~mm} \times 40 \mathrm{~mm}$

$\mathbf{P}_{\mathrm{D}}, \quad \mathbf{P}_{\mathrm{u}} \quad$ Pressure Transducers - Kistler 4045A5 (25 $\mathrm{mV} / \mathrm{bar} / \mathrm{mA}$ sensitivity, natural frequency $\approx 80 \mathrm{kHz}$ ) used in conjunction with a National Instruments 6110 series data logger

Q. Fibre Optic Delivery of Laser Light

$\mathbf{R}_{\mathrm{c}}, \mathbf{R}_{\mathrm{s}}$, Cylindrical \& Spherical Lenses 
179 Figure 1 shows the pneumatics assembly within the test rig. Components $A-J$ were linked by 180 nylon hoses (ID $8 \mathrm{~mm}$ ). The Nexthaler® device was positioned in a vertical orientation with suction 181 applied, via the optical access adaptor $\mathrm{J}$, in the same direction. This arrangement was defined by

182 the needs of the experiment, but did not affect the operation of the device which is flow-dominated.

183 Although patients' inhalation profiles are individual and complex functions of time and inspiration 184 (Kenyon et al., 1999; Miller et al., 2000), the transient air flow through a device can be more simply 185 characterised in terms of the peak inhalation flow rate $\left(Q_{\max }\right)$, the total inhaled air volume, inhalation 186 duration and flow rate acceleration, (Everhard et al., 1997; Yakubu et al., 2013). Furthermore, 187 many dry-powder inhalers emit the formulation rapidly from the device before completion of the 188 initial flow acceleration phase of inspiration (Everhard et al., 1997; Burnell et al., 1998; Finlay \& 189 Gehmlich, 2000). For our purpose of studying the phenomena of metered powder release, 190 fluidisation and transport to the device mouthpiece, it was considered sufficient to generate 191 controlled suction (inspiration) profiles up to the peak flow rate $\left(Q_{\max }\right)$ and ignore the subsequent 192 tailing portion of the inspiration cycle, which is unlikely to contribute to the powder dose emission 193 event. Air flow profiles selected for investigation with the test rig were set in terms of $Q_{\max }(40,60$ \& $\left.19480 \mathrm{I} \cdot \mathrm{min}^{-1}\right)$ and rise time, $\mathrm{t}_{\text {rise, }}(0.3,0.7$ and $1.2 \mathrm{~s})$ between initiation of suction and achievement of 195 steady state pressure differentials, $\left(P_{U}-P_{D}\right)$. These parameters are consistent with the majority of 196 the in vivo inhalation profiles (peak inspiratory flow and time to peak inspiratory flow) reported for a 197 cohort of 41 adult asthmatics through Nexthaler®, (Casaro et al., 2014), and also enabled 198 systematic variations of peak air flow rates and the initial rates of change of air flow with respect to 199 time. Differential suction pressures across the Nexthaler ${ }^{\circledR}$ device were measured using a Kistler 200 pressure transducer mounted in the optical adaptor (referencing the ambient pressure before 201 suction). Simultaneous flow rate data were acquired by means of a thermal mass flow meter. This 202 information was used to characterise the accelerating flow. Suction was produced by first 203 evacuating the 20 litre vacuum vessel with the vacuum pump (A) to a pressure below $0.1 \mathrm{kPa}$ and 204 then isolating it using the ball valve (B). This entrapped vacuum generates the necessary pressure 
205 differentials for suction periods up to 4 seconds without the requirement for a high-flow vacuum 206 pump. The pneumatic system comprises the following functional components. The interchangeable 207 orifice sonic flow restrictor, (D), prevents turbulent pressure variations at the device mouthpiece by 208 maintaining the ratio of downstream to upstream pressure across the restrictor $<0.5$ for all flow 209 conditions. The setting of the flow control valve, (E), allows variation of $Q_{\max }$ from 40 to $80 \mathrm{I}^{\mathrm{m}} \mathrm{min}^{-1}$. 210 The rapid switch on/off solenoid-controlled ball valve, $(F)$, has minimal flow resistance when fully 211 open. Adjustment of the variable volume unit, $(G)$, enables the rise time, $t_{\text {rise }}$, to be set between 0.3 212 and $1.2 \mathrm{~s}$. The steady-state flow rate $Q_{\max }$ is monitored by the thermal mass flowmeter $(H)$. The $2131 \mu \mathrm{m}$ particle filter, (I), collects fluidised powder and prevents deposition on the surfaces of the mass 214 flow meter and blockages further downstream.

215 The 20 I volume of the vacuum vessel was sufficiently large to maintain a pressure ratio of 0.5 216 across the sonic flow restrictor and ensure test durations between 0 and 4 seconds at the chosen 217 maximum value of flow rate. The pressure transducer, $\left(P_{u}\right)$ mounted on the surface of the laser 218 illumination box measures the suction pressure at the Nexthaler® mouthpiece.

\subsubsection{Test Rig Optics for Imaging Events Within Nexthaler ${ }^{\circledR}$}

221 High-speed imaging of the functionality of the dose protector mechanism and powder entrainment

222 from the dosing cup into the air stream was carried out by examining the region inside the device 223 where the metered dose of formulation is initially entrained by the air flow. A high-speed camera (N) 224 was used in conjunction with a copper-vapour laser light source (Type LS20-10, Oxford Lasers, 225 Oxford, UK). The laser light was directed to the image area by fibre-optic transmission as shown 226 schematically in Figures 2a \& b. Light pulses of 25 ns duration, were synchronized with the camera 227 recording at 10,000 frames. $\mathrm{s}^{-1}$ at a resolution set to 512 by 512 pixels, equivalent to an imaging 228 area approximately $5 \mathrm{~mm}$ by $5 \mathrm{~mm}$. The imaging configuration utilised a $105 \mathrm{~mm}$ Nikkor macro-lens 229 with an aperture setting of f11 resulting in a pixel resolution limit of approximately $10 \mu \mathrm{m}$. 
Figure 2. Schematic of Optical Equipment Set-up for Imaging Formulation Entrainment from

\section{2.3.4 Particle Plume Imaging \& Flow Field Velocimetry at Nexthaler ${ }^{\circledR}$ Mouthpiece Exit}

236 High-speed imaging of the particle plume at the exit of the device mouthpiece to investigate its 237 temporal and spatial structure and two-dimensional high-speed velocity measurement of the ex238 mouthpiece flow field using particle image velocimetry (PIV), were carried out using the 239 experimental arrangement, shown schematically in Figures 3a-b.

\section{INSERT FIGURE 3 HERE}

Figure 3: Schematic of Optical Equipment Set-up used for Nexthaler® Ex-mouthpiece Plume

246 Here, the copper-vapour laser was replaced by a Pegasus dual-cavity neodymium-doped yttrium247 lithium fluoride laser, Nd:YLF, (New-wave Research Inc. Fremont CA, USA), as the light source. 248 This laser enabled illumination using either a single cavity, producing an even pulse separation time 249 for use in the imaging work, or from both cavities, allowing the separation time between each cavity 250 to be adjusted for the velocity measurement work. The light from the laser for the ex-mouthpiece 251 work was formed into a light sheet using a spherical-cylindrical lens combination. The light sheet 252 was directed so that it intersected the exit-plume from the device through the centre-line of the 253 orifice, in-line with the flow direction. The high-speed imaging of the plume was carried out at a camera speed of 3000 frames. $\mathrm{s}^{-1}$ with a resolution of 1024 by 1024 pixels providing an imaging area $25522 \times 22 \mathrm{~mm}$ and pixel resolution of approximately $22 \mu \mathrm{m}$. This resolution limit is significantly larger 
256 than the smallest particles in the flow; however, due to diffraction small particles appear much larger

257 and cover more than one pixel in the image.

258 In order to investigate the temporal development of the air flow through the Nexthaler® DPI, particle

259 image velocimetry was applied to the region of the flow near the exit of the mouthpiece. For these 260 tests, the device was primed prior to suction but no powder was present. The particles used to trace 261 the air flow, and thus provide the basis for velocity quantification, were olive oil droplets nominally $2621 \mu \mathrm{m}$ diameter, introduced into the air surrounding the Nexthaler $\AA$ device via a six-jet atomiser 263 (model 9306A TSI Instruments UK), and drawn through the device during the suction event. Olive 264 oil particles were selected for their light-scattering properties and ability to enable accurate tracking 265 of the local air-motion through the device even under highly turbulent conditions. The recorded 266 particle images were analysed using DaVis software (LaVision $\mathrm{GmbH}$ ) to calculate the flow-field 267 velocity vectors.

268 PIV measurements utilised the same equipment set-up, but with the triggering of the laser and 269 camera altered to create pairs of images. Each image pair had a short and controllable time 270 separation $(2-8 \mu \mathrm{s})$ between the first and second image, enabling calculation of particle velocity 271 from their spatial displacement. Recording of the particle images was carried out at either 1000 or 2722000 frames.s $\mathrm{s}^{-1}$, providing velocity`measurements at either 500 or 1000 vector fields per second, 273 depending on the duration of the rise-time being examined.

\section{3. Results and Discussion}

\subsection{Differential (Suction) Pressure Time Profiles}

277 Figure 4 shows the differential pressure-time profiles recorded for eight flow rate, $\left(Q_{\max }\right)$ - rise time, 278 (trise) combinations achieving steady state pressure differential. Due to limitations imposed by the 279 design of the variable volume unit in the suction system, it was not possible to produce a dataset for 280 a $0.3 \mathrm{~s}$ rise time with a $40 \mathrm{I} \cdot \mathrm{min}^{-1}$ maximum flow rate. The profiles in the upper panels, (ai, aii, aiii), 
281 were obtained using an unfilled Nexhaler® device; those in the lower panels, (bi, bii, biii), were 282 obtained using a filled Nexthaler ${ }^{\circledR}$ with the metering cup primed by opening the device cover, 283 (Corradi et al., 2014). The shapes of the eight profiles in Figure 4 differ from those of Chavan \& 284 Dalby (2002), which show linear flow-time relationships during the flow acceleration phase until the 285 steady state is achieved at $Q_{\max }$. Such a relationship between flow rate and time is easy to describe 286 mathematically, but involves a discontinuity in the flow acceleration at the changeover between the 287 initial phase when the flow ramps up and the constant steady-state flow. Whilst a linear ramp profile 288 may be suitable for quality assurance testing, it is well known that human inhalation profiles vary in 289 a quasi-parabolic manner reaching a maximum before tailing.

\section{INSERT FIGURE 4 HERE}

Figure 4.: Effect of Variation in flow rate maximum and rise time on suction pressure-time profiles though Nexthaler® ,

(a) without powder loading but with metering cup primed, (b) with powder loading and metering cup primed. (green, red, blue traces; $Q_{\text {MAX }}=40,60,80$

298 In the present system, the initial portion of the profile is similar for each flow rate for a given rise 299 time. Thereafter the differential pressure traces curve towards the steady state plateau. The theory 300 of pneumatic circuits and transmission lines shows that this behaviour can be understood in terms 301 of the inertance, capacitance and resistance of the test rig's circuit components and its fluid content. 302 The traces confirm that independent variation of the peak flow rate $Q_{\max }$ and rise time of the suction 303 profile has been achieved (i.e. the peak flow rate can be varied while maintaining a constant rise 304 time), allowing a range of different flow profiles to be achieved.

305 Figures 4 (b) i-iii show that when the Nexthaler® device is filled and primed, and therefore with the 
307 pressure-differential profiles through the device differ slightly from those obtained with primed but

308 un-loaded devices, (Figures 4 (a) i-iii). The appearance of discontinuities (arrowed), indicates that a

309 change in the rate of change of pressure differential is induced by the resultant particle entrainment.

\subsection{Dose protector functionality and powder fluidisation}

312 Figure 5 presents high-speed images of the functionality of the dose protector mechanism and the 313 powder entrainment. The dosing (metering) cup shows as a circular region inside the bright grey 314 image of the bottom of the device, as seen through the circular mouthpiece orifice. The powder 315 dose is initially located in the centre of the dosing cup, where it shows as a white, granular region. 316 Under the test conditions shown, $\left(Q_{\max } 60 \mathrm{I} \cdot \mathrm{min}^{-1}, 0.3\right.$ second rise time), the dose protector covers 317 the powder dose until $40 \mathrm{~ms}$ after the initiation of suction. Thereafter, the suction pressure

318 differential inside the Nexthaler ${ }^{\circledR}$ has built up sufficiently to trigger the breath-actuated mechanism, 319 which then displaces the dose protector to expose the metered powder to the air flow in the device's 320 swirl-chamber below the mouthpiece. The powder bed starts to rotate immediately, under the 321 influence of the developing vortex flow in the vicinity of the dosing cup. The bulk of the powder 322 dose is rapidly fluidised during the first phase of the interaction, which has a duration of around 20 $323 \mathrm{~ms}$ after the dose protector is removed. A small proportion of the particles remains deeper inside

324 the dosing cup at this stage. This region is less exposed to the air flow and this powder remnant is, 325 therefore, fluidised much more gradually.

\section{INSERT FIGURE 5 HERE}

Figure 5: Images of dosing (metering) cup region showing powder fluidisation and dose protector 
332 Particle fluidisation during this second phase appears to be stochastic. The aerodynamic forces are

333 insufficient to pick up the large carrier particles, but the forces are fluctuating as a consequence of

334 the high turbulence levels induced in the swirl chamber. Occasionally one or two particles are

335 forced to move up towards the top edge of the dosing cup where they can be entrained by the flow

336 and transported upwards via the swirl chamber to the mouthpiece. Under the prevailing

337 experimental conditions, Figure 5 shows that the dosing cup is completely empty approximately 300

338 ms after the start of the flow.

\subsection{Ex-mouthpiece aerosol plume - imaging}

341 The imaging work carried out in section 3.2 has shown that after entrainment into the air flow, the 342 powder is rapidly transported through the swirl chamber into the outlet tube towards the device

343 mouthpiece. Within the swirl chamber high levels of swirl are induced by the internal flow passage

344 geometry of the Nexthaler®. The air, and hence the particles, are expected to follow spiral paths

345 with a large circumferential velocity component superposed on the upward axial velocity component 346 towards the mouthpiece. The density of the lactose and drug solids is much higher than the air

347 density, so the aerosol plume will be most dense near the surrounding walls, as can be seen in the

348 image displayed in Figure 6. The large carrier particles experience a more pronounced outward 349 displacement, whereas the fines are more uniformly distributed throughout the aerosol.

350 A typical single frame image of the emitted aerosolised particles, illuminated by the laser sheet positioned across the centreline of the mouthpiece, is shown in Figure 6. For clarity, this image and

352 Figure 7 have been inverted, to show the particles in the light sheet as dark regions on a light

353 background. The general appearance of the cloud suggests that the flow is highly agitated and 354 turbulent, as confirmed by examination of the complete video. The larger particles in the placebo 355 blend experience a more pronounced outward displacement whereas fines are more uniformly 356 distributed. This is to be expected, since the design of the internal flow passage geometry of 357 Nexthaler® induces a spiral path with a large circumferential velocity component superimposed on 
358 the upward axial velocity component to the air drawn through the device by the inhalation

359 manoeuvre, which is transmitted to the fluidised particles. The larger the particles, the greater the 360 unit mass and the greater the centrifugal force imposed.

\section{INSERT FIGURE 6 HERE}

364 Figure 6: Typical Single Frame from High Speed Video Capture of Powder Emission from

368 To characterise the temporal release of the powder from the device mouthpiece, the pixel intensities

369 within a defined rectangle across the centre of the device mouthpiece, (Figure 6), were summed for

370 each frame, $\left(\sum I_{P x}\right)$. The individual $\sum I_{P X}$ values for a given frame were then normalised against the 371 maximum value obtained in the entire ensemble of frames in the video from the start to the end of 372 suction pertaining to that single dose powder discharge from the Nexthaler® unit. Plotting the 373 normalised intensities against time, (Figure 7) thus provides a quantitative description of the powder 374 emission kinetics. Normalising the summed intensities in this manner allows quantitative 375 comparison of the effects of $Q_{\max }$ and rise time on the powder emission kinetics by eliminating the 376 influences of intra-device variations of unit dose metering and temporal variation in laser pulse 377 energy.

378 Figure 7a compares the pressure differential (pressure drop, $\Delta \mathrm{P}$ ), generated across the Nexthaler $\AA$ 379 with the normalised intensity profiles of powder emission during the air flow acceleration phase of 380 an event over a rise time of $0.3 \mathrm{~s}$ resulting in a steady-state flow rate, $\left(Q_{\max }\right)$, of $60 \mathrm{I} . \mathrm{min}^{-1}$. Figure $3817 \mathrm{~b}$ presents a selection of (inverted) particle images captured between $30-130 \mathrm{~ms}$ after 382 commencement of flow, with the corresponding acquisition time indicated on each frame and its 
383 location on the abscissa of Figure 7a. The normalised intensity profiles suggest that powder

384 emission takes place in four phases characterised by:

385 (i) a small peak (A), normalised intensity $\sim 0.2$ around $40 \mathrm{~ms}$,

386 (ii) a large peak (B), normalised intensity maximum 1.0 around $60-70 \mathrm{~ms}$, which is associated 387 with most of the powder emission,

388 (iii) a second small peak (C), normalised intensity maximum $\sim 0.3$ around $80 \mathrm{~ms}$, followed by,

389 (iv) a slow decline in normalised intensity, (D), over 90 - 300 ms with some minor spikes commensurate with the emission of small bursts of fine particles and a few larger aggregates, (see Figure 7b, e.g. Frame 642).

392 Imaging of the dosing cup region, (see section 3.2 figure 5), showed that the bulk of the powder 393 entrainment takes place between 40 and $60 \mathrm{~ms}$. The time required to transport the powder from the 394 dosing cup to the mouthpiece exit explains the delay in appearance of the large intensity peak B, 395 (Figure 7), at 60-70 ms. The pressure differential across the Nexthaler $\AA$, (Figure 7a), shows a 396 discontinuity coinciding with the large intensity peak B; equivalent discontinuities for powder-filled 397 devices are also shown in figures $4 b(i-i i i)$. These can be attributed to the substantial amounts of 398 flow energy required to lift the particles from the dosing cup to the mouthpiece and the increased 399 energy dissipation associated turbulent multi-phase flows. The particle intensity images, (Figure $400 \mathrm{7b}$ ), also show that peak $\mathrm{C}$, around $80 \mathrm{~ms}$, is linked with the emission of large particles, or 401 aggregates which are heavier and will therefore be held up inside the device for a longer period of 402 time than the finer material. Finally, it should be noted that a small quantity of finer particles is 403 visible in the images taken at 30 and $40 \mathrm{~ms}$, times when the dose protector still covers the powder 404 dose. Careful inspection of high-speed images of the dosing cup region reveals that some air flows 405 through a narrow gap created by a small uplift of the dose protector due to the build-up of suction in 406 this region. This air flow succeeds in dislodging some of the fine material and initiating premature 407 release. However, as evidenced by the normalised intensity profile peak areas, (A relative to $B+C)$, 408 the total amount of this premature emission is very small compared with the release of the majority 409 of the powder dose. 


\section{PLEASE ROTATE LEFT}

414 To examine the effect of the flow conditions on powder dose emission, the temporal behaviour of 415 the normalised intensity profiles was compared across all the test conditions used in this study. 416 Figures $8 \mathrm{a}-\mathrm{c}$ show the profiles with rise time of $0.3,0.7$ and $1.2 \mathrm{~s}$, respectively. All three plots show 417 the time to achieve peak value, (1.0), of normalised-intensity, $\left(t_{\max }\right)$, increases with increase in rise 418 time, but decreases with increase in $Q_{\max }$, confirming that flow rate acceleration controls powder 419 emission rate. The width of the main intensity peak, measured from the point of rapid increase in 420 intensity gradient between peaks A and B to the point of inflection between peaks B and C, 421 increases from about $15 \mathrm{~ms}$ to $25 \mathrm{~ms}$ as the rise time increases from $0.3 \mathrm{~s}$ to $1.2 \mathrm{~s}$. However, the 422 peak width changes little with flow rate, i.e. for the $1.2 \mathrm{~s}$ rise time case, the peaks are all between 23 423 and $25 \mathrm{~ms}$.

424 The early, small peak (i.e. Peak A in Figure 7) occurs 40-50 ms after the suction is switched on for 425 all test conditions, before movement of the dose protector was observed in the high-speed images. 426 As noted earlier, the small quantity of fines emission at this stage will occur as soon as a narrow 427 flow path underneath the dose protector admits sufficient air to pick up fines from the powder dose. 428 However, the intensity data demonstrates the magnitude of this early peak diminishes with 429 increasing rise time.

430 Comparison of the pressure and image-intensity traces shown in figure 7 clearly demonstrates that 431 the small discontinuity found in the differential-pressure trace coincides with the start of the large 432 peak in normalised plume-intensity (peak B). This coincidence is also found in all of the traces 433 detailed in figures 4 and 8, which supports the view that the pressure discontinuities are associated 434 with the release of the powder-dose into the flow, not the initiation of dose protector movement. The 
435 delay in the dose-protector movement relative to the start of suction, and hence dose-release, is 436 dependent on the suction profile and as such varies with both max flow-rate and rise-time. The 437 design of the Nexthaler® DPI is such that the dose protector should withdraw when a pre-set 438 suction of $2 \mathrm{kPa}$ below ambient is reached; comparison of event timings in Figures 4, 5 and 7 shows 439 that the dose is consistently emitted very shortly after sufficient suction occurs to move the dose 440 protector. Figure 4 suggests that, for cases where the peak flow rate is $40 \mathrm{I}_{\mathrm{min}} \mathrm{m}^{-1}$, the actual trigger 441 point of the dose protector is slightly below $2 \mathrm{kPa}$. This pressure differential is very close to the limit 442 of device actuation, which explains why the time from the start of the event flow to the main 443 normalised intensity peak (shown in figure 8) is much longer than at peak flow rates of 60 and $44480 \mathrm{I} \cdot \mathrm{min}^{-1}$. Achieving a high peak flow rate or a short rise time, on the other hand, requires a large 445 rate of change of pressure. Inertia of the dose protector and the powder dose will tend to resist 446 rapid movements somewhat, consequently suction pressures just above $2 \mathrm{kPa}$ are needed to 447 achieve dose protector movement and powder release at 60 and $801 . \mathrm{min}^{-1}$ flow rates and shorter 448 rise-time (also see Figure 4).

453 Figure 8 - Normalised intensity profiles as function of time for flow conditions: peak flow rate 40 454 I. $\mathrm{min}^{-1}$ (green traces), $60 \mathrm{I} \cdot \mathrm{min}^{-1}$ (red traces) and $80 \mathrm{I} \cdot \mathrm{min}^{-1}$ (Blue traces). Rise time: (a) $0.3 \mathrm{~s}$, (b) 0.7 455 $\mathrm{s},(\mathrm{c}) 1.2 \mathrm{~s}$ 
459 Axial and radial velocity components were measured across a plane perpendicular to the device 460 exit, along the centreline of the mouthpiece. The measurement region is $20 \mathrm{~mm} \times 20 \mathrm{~mm}$ in size, 461 with single vectors calculated over interrogation regions approximately $0.6 \mathrm{~mm} \times 0.6 \mathrm{~mm} ; 50 \%$ 462 overlap of the interrogation regions provided a vector spacing of $0.3 \mathrm{~mm}$ across the field. An 463 example of a typical vector field is shown in Figure 9 for the flow conditions $Q_{\max } 60$ I.min ${ }^{-1}$, rise time, $4640.3 \mathrm{~s}$; the magnitude of the flow velocity is indicated by means of the colour scale. The maximum 465 velocity of $40 \mathrm{~m} \cdot \mathrm{s}^{-1}$ is coloured white.and appears around radius $\pm 5 \mathrm{~mm}$ just outside the 466 mouthpiece.

467 A slight asymmetry is evident with somewhat larger region of high velocity on the right hand side of 468 the velocity field images (see figure 10b). If, as surmised earlier, the air follows spiral paths inside 469 the device and develops concentrated regions of high-speed flow at the periphery, this accounts for 470 the reverse flow in evidence around the centreline of the mouthpiece exit, (see Figure 9 near the red 471 line at radius zero). This is a well-known secondary flow pattern at high swirl levels, which 472 generates high shear in the internal flow passages. After exiting the mouthpiece, the unbalanced 473 centrifugal force on the rotating flow causes the fastest fluid to move radially outwards. The flow 474 interacts with the stationary surroundings, which generates additional shear stress on the external 475 flow, which in turn causes turbulent eddies, several of which are clearly visible in Figure 9. 
Figure 9 - Typical PIV vector field with analysis line position, $Q \max =60 \mathrm{I} \cdot \mathrm{min}^{-1} \mathrm{t}_{\text {rise }}=0.3 \mathrm{~s}, 0.23 \mathrm{~s}$ after start of suction (arrows indicate 2D direction of flow)

484 Quantitative information was extracted from the 2D vector flow fields by calculating a mean axial 485 velocity component $(\bar{V})$ as follows:

$$
\bar{V}=\sum_{i} V_{i} \Delta A_{i} / A_{L}
$$

487 where $V_{i}=$ velocity at location i, $\Delta A_{i}=$ area of the image plane used in the velocity measurement at 488 location $i, A_{L}=$ total area used for the velocity measurements that intersect the analysis line; points $489 i$ are spaced uniformly along a line parallel to the device exit orifice (red line in Figure 9).

491 Since turbulent eddies cause large instantaneous variations in the local axial velocity, smoothed $\bar{V}$ 492 values are reported, to produce more meaningful data. These were computed using a shifting time 493 average over ten vector fields, corresponding to an averaging time of $10 \mathrm{~ms}$.

495 Figure 10a shows smoothed mean axial velocity-time profiles obtained for Nexthaler® during the 496 flow acceleration phase with the same flow conditions as the high-speed imaging tests reported 497 above (section 3.3, Figure 7) i.e. steady-state air flow rate conditions $Q_{\max }, 60$ I.min ${ }^{-1}$, rise time $0.3 \mathrm{~s}$ 498 along with the recorded differential pressure. It should be noted that the averaging of these axial 499 velocity components along the analysis line (see figure 9) does not exactly represent the mean axial 500 flow velocity at the device-exit since the analysis line was extended beyond the $8 \mathrm{~mm}$ diameter 501 mouthpiece (figure 9) to off-set the turbulent and spreading nature of the post-orifice flow and only 502 represents the narrow section of flow illuminated by the laser sheet. However, the increase of the 
503 mean velocity is found to correlate well with the decrease of the measured pressure differential,

504 suggesting that the post-processed average axial velocity across the sample line (shown in figure

505 10) is a good indication of the general changes of the flow rate of the air drawn through the device 506 as a function of time.

507 Figure 10b presents a selection of PIV velocity vector fields with the corresponding time indicated

508 on each frame as well as the location on the time axis. The velocity scale is the same for all 509 images, white corresponding to $40 \mathrm{~m} \cdot \mathrm{s}^{-1}$ and dark blue to zero $\mathrm{m} \cdot \mathrm{s}^{-1}$, respectively. The maximum 510 value is clearly lower in the first image $(25 \mathrm{~ms})$ when flow rate is still increasing, but otherwise the

511 PIV images show the same flow features noted earlier for Figure 9 with flow asymmetry toward the 512 right of the images, possibly induced by the internal flow paths within the Nexthaler@ device.

\section{4. Conclusions}

518 In this study, we have successfully applied optical diagnostics to characterise various aspects of the 519 Nexthaler ${ }^{\circledR}$ DPI and demonstrated how detailed information about the device functionality and 520 powder dose emission can be obtained by means of these techniques.

521 Results from the study have shown that fluidisation of the bulk of the powder occurred shortly after

522 the withdrawal of the dose protector. Powder was found to arrive at the mouthpiece exit after a 523 short delay due to transport of the powder from the dosing cup to the mouthpiece exit by the air 524 stream. The powder dose is mainly emitted in a short burst, which occurs after the withdrawal of the 525 dose protector, with a duration between 15 and $40 \mathrm{~ms}$, dependent upon $\mathrm{Q}_{\max }$ and rise time (flow rate 526 acceleration). Thereafter there is an emission of larger particles with residual fine material for a 527 further 100 - 150 ms. Most of the powder dose has been aerosolised within $100 \mathrm{~ms}$ of flow initiation. 
528 The visualisation study also revealed that a small fraction of the fines is emitted whilst the dose 529 protector still covers the dosing cup.

530 High-speed imaging studies have shown that a highly turbulent, rotating flow is created in the 531 internal passages of Nexthaler®. These high swirl levels generate a highly sheared, turbulent flow 532 inside the device, which interacts with the stationary surrounding air just outside the mouthpiece 533 generating additional turbulence within the emitted plume. Moreover, the centrifugal force flings the 534 larger carrier particles radially outwards towards the walls of the internal passages increasing the 535 probability of wall impacts. 
538 - Acerbi D., Brambilla G., Lewis D., Meakin B. (2007). ‘Gaining approval to market 539 therapeutically equivalent inhalers in the EU: an industry perspective', Proc. Respiratory $540 \quad$ Drug Delivery Europe pp. 127-140.

541 - de Boer A.H., Gjaltema D., Hagedoorn P. (1996). 'Inhalation characteristics and their effects 542 on in-vitro drug delivery from dry powder inhalers. Part 2: effects of peak flow rate (PFIR) 543 and inspiration time on the in-vitro drug release from there different types of commercial dry 544 powder inhalers', International Journal of Pharmaceutics, Vol. 138, pp. 45-56.

545 - British National Formulary 68, (2014). Section 3. Respiratory System, pp. 180-201.

546 - Burnell P.K.P, Grant A.C., Haywood P.A., Prime D., Sumby B.S., (1998). 'Powder inhalers 547 exploring the limits of performance', Respiratory Drug Delivery VI, pp. 259-266.

548 - Casaro D., Brambilla G., Pasquali I., Sisti V., (2014). 'In vitro aerosol performances of $549 \quad$ NEXThaler ${ }^{\circledR}$ using representative inhalation profiles from asthmatic patients', Proceedings 550 of Respiratory Drug Delivery 2014. Vol. 2, pp. 375-380.

551 - Chavan V. and Dalby R. (2002). 'Novel system to investigate the effects of inhaled volume and rates of rise in simulated inspiratory air flow on fine particle output from a dry powder inhaler', AAPS Pharmaceutical Science and Technology, Vol. 4, No. 2, pp. 1-6.

- Church T.K., Brambilla G., Lewis D.A., Meakin B.J., Poli G. (2010), 'Sub-micron particles: an effective menas of achieving bronchodilation' Proc. Respiratory Drug Delivery, Vol 2 pp 509512

- Clark A.R. and Hollingsworth A.M. (1993). 'The relationship between powder inhaler resistance and peak inspiratory conditions in healthy volunteers: implications for in-vitro testing', Journal of Aerosol Medicine, Vol. 6, pp. 99-110. M., Usmani O.S. (2014). 'NEXThaler, an innovative dry powder inhaler delivering an extrafine fixed combination of beclometasone and formoterol to treat large and small airways in asthma', Expert Opinion on Drug Delivery, Vol. 11, No. 9, pp. 1497-1506. 
- Dunbar C.A., Hickey A.J. and Holzner P. (1998). 'Dispersion and characterization of pharmaceutical dry powder aerosols', KONA Powder and Particle, Vol. 16, pp. 7-45

- Electronic Medicines Compendium, Accessed August 2015.

- Everard, M.I., Devadason, S.G., Le Souef, P.N. (1997). 'Flow early in the inspiratory manoeuvre affects the aerosol particle size distribution from a Turbuhaler'. Respiratory Medicine, Vol. 91, pp. 624-628.

- Finlay W.H. (2001), 'The mechanics of inhaled pharmaceutical aerosols - an introduction', Academic Press, San Diego.

- Finlay W.H. and Gehmlich M.G., (2000). 'Inertial sizing of aerosol inhaled from two dry powder inhalers with realistic breath patterns versus constant flow rates', International Journal of Pharmaceutics, Vol. 210, pp. 83-95.

- Friebel, C., Steckel, H., Muller, B.W. (2012). Rational design of a dry powder inhaler: device design and optimization. Journal of Pharmacy and Pharmacology, Vol. 64, pp. 1303-1315.

- Hawksworth, G.M., James, I., Chrystyn, H., (2000). 'Characterization of the inspiratory manoeuvre when asthmatics inhale through a Turbohaler pre- and postcounselling in a community pharmacy'. Respiratory Medicine, Vol. 94, pp. 501-504.

- Hindle M. and Byron P.R. (1995). 'Dose emission from marketed dry powder inhalers', International Journal of Pharmaceutics, Vol. 116, pp. 169-177.

- Kuna P., Mirco G., Lucci G., Scuri M., Acerbi D., Iwona S. (2015). 'Pharmacokinetics and pharmacodynamics of an extrafine fixed pMDI combination of beclometasone dipropionate/formoterol fumarate in adolescent asthma', British Journal of Clinical Pharmacology, Vol 79 pp 1365-2125.

- Kenyon D., Schenkel E., Miller D., Angelini B., Skoner D. (1999). 'Assessment of inspiratory 588 flow rates and rise time data in patients with asthma', European Respiratory Journal, Vol. 14, pp. 525s.

- Laube B.L., Janssens H.M., de Jongh F.H.C., Devadason S.G., Dhand R., Diot P., Everard M.L., Horvath I., Navalesi P., Vosbaar T. and Chrystyn H. (2011). 'ERS/ISAM task force 
consensus statement: recommendations on what pulmonary specialist should know about the new inhalation therapies, European Respiratory Journal, Vol. 37, pp. 1308-1331.

- Miller D., Schenkel E., Kenyon D., Harrison J. (2000). 'Airflow profiles and inhaler technique with the new mometasone furoate dry powder inhaler (MF-DPI)', Journal of Allergy and Clinical Immunology, Vol 105, pp. S16.

- Newman S.P. and Busse W.W. (2002). ‘Evolution of dry powder inhaler design, formulation and performance', Respiratory Medicine, Vol. 96, 293-304.

- Ngoc NTQ, Chang L, Jia X, Lau R (2013). ‘Experimental investigation of design parameters on dry powder inhaler performance', International Journal of Pharmaceutics, Vol 457, pp. 92100.

- Pasquali I., Brambilla G., Long E.J., Hargrave G.K. and Versteeg H.K. (2012). 'A visualisation study for the aerosol generation in NEXThaler®', Poster abstract MN-1150, Proceedings AAPS Conference, October 2012, Chicago, IL.

- Physicians' Desk Reference 2015. PDR eBook

- Staniforth J.N. (1995) 'Performance-Modifying Influences in Dry Powder Inhalation Systems', Aerosol Science and Technology, Vol. 22, No. 4, pp. 346-353

- Sweeney L.G. and Finlay W.H. (2007). 'Lift and drag forces on a sphere attached to a wall in a Blasius boundary layer', Journal of Aerosol Science, Vol. 38, pp. 131-135.

- Voss, A., Finlay, W.H. (2002). 'Deagglomeration of dry powder pharmaceutical aerosols'. International Journal of Pharmaceutics, Vol. 248, pp. 39-50.

- Wang Z., Lange C.F. and Finlay W.H. (2004). 'Use of an impinging jet for dispersion of dry powder inhalation aerosols', International Journal of Pharmaceutics, Vol. 275, pp. 123-131.

- Xu Z., Mansour H.M., Mulder T., McLean R., Langridge J. and Hickey A.J. (2010). 'Heterogeneous particle deaggregation and its implication for therapeutic aerosol performance', Journal of Pharmaceutical Sciences, Vol. 99, pp. 3442-3461. 
616 - Xu Z. and Hickey A.J. (2013). 'A comparison of aerosol performance using standardized 617 entrainment tubes vs. dry powder inhaler devices' KONA Journal of Powder and Particle 618 Technology, Vol. 30, pp. 201-210.

619 - Yakubu S.N., Assi K.H., Chrystyn H. (2013). 'Aerodynamic dose emission characteristics of 620 dry powder inhalers using Andersen Cascade Impactor with a mixing inlet: The influence of 621 flow and volume', International Journal of Pharmaceutics, Vol. 455, pp. 213-218.

622 - Zhou Q.T, Armstrong B., Larson I., Stewart P.J., Morton D.A.V. (2010). 'Understanding the 623 influence of powder flowability, fluidization and de-agglomeration characteristics on the 624 aerosolization of pharmaceutical model powders', European Journal of Pharmaceutical 625 Sciences, Vol. 40, pp. 412-421. 
GRAPHICAL ABSTRACT

OF

Optical diagnostics study of air flow and powder fluidisation in Nexthaler®

Part I: Studies with Lactose Placebo Formulation

Pasquali I. ${ }^{1}$, Merusi C. ${ }^{1}$, Brambilla G. ${ }^{1}$, Long E.J. ${ }^{2}$, Hargrave G.K. ${ }^{2}$, Versteeg H.K. ${ }^{2 \dagger}$

${ }^{1}$ ChiesiFarmaceuticiS.p.A., Parma, Italy

${ }^{2}$ Wolfson School of Mechanical and Manufacturing Engineering, Loughborough University, Loughborough, United Kingdom 


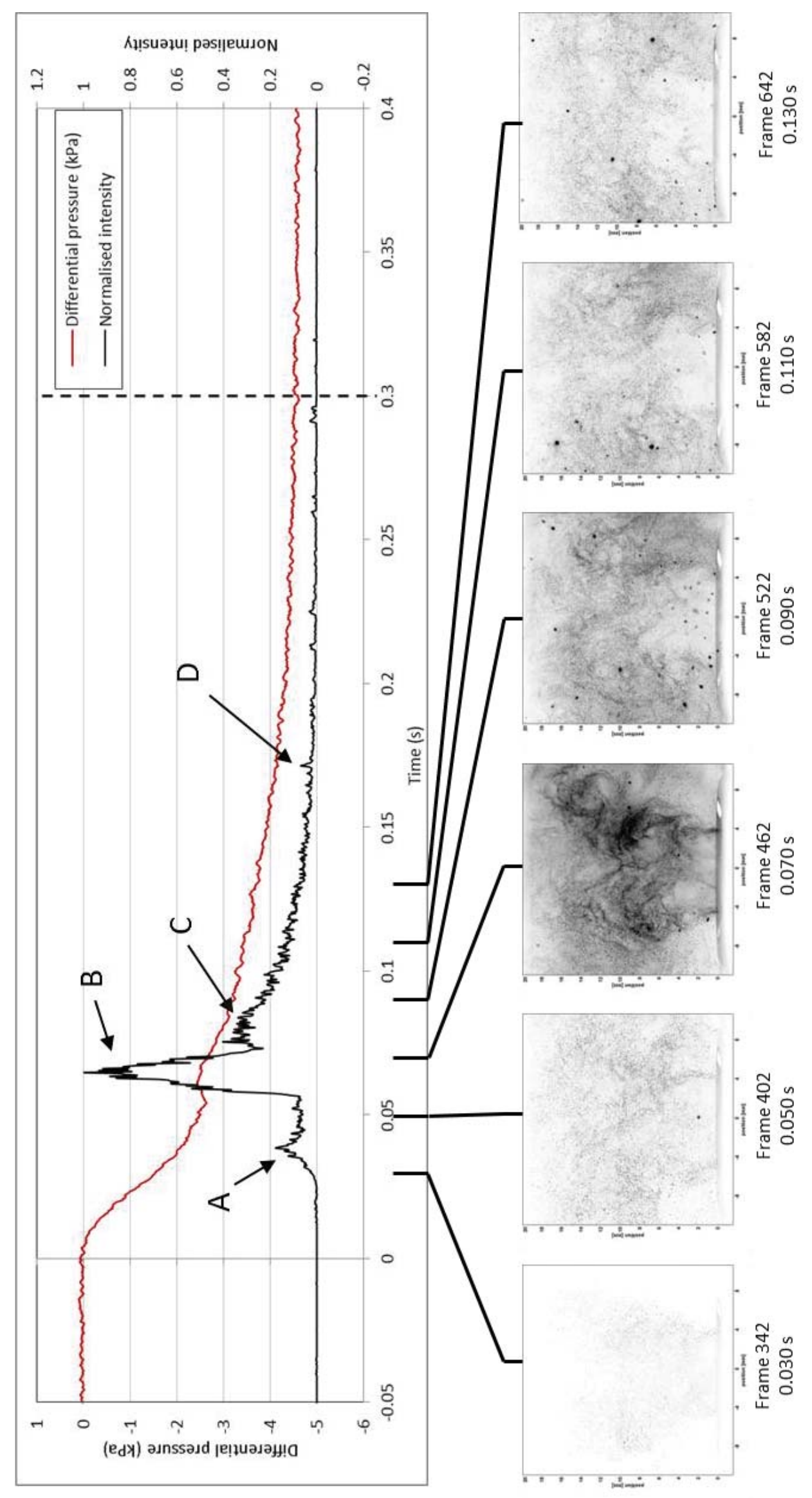




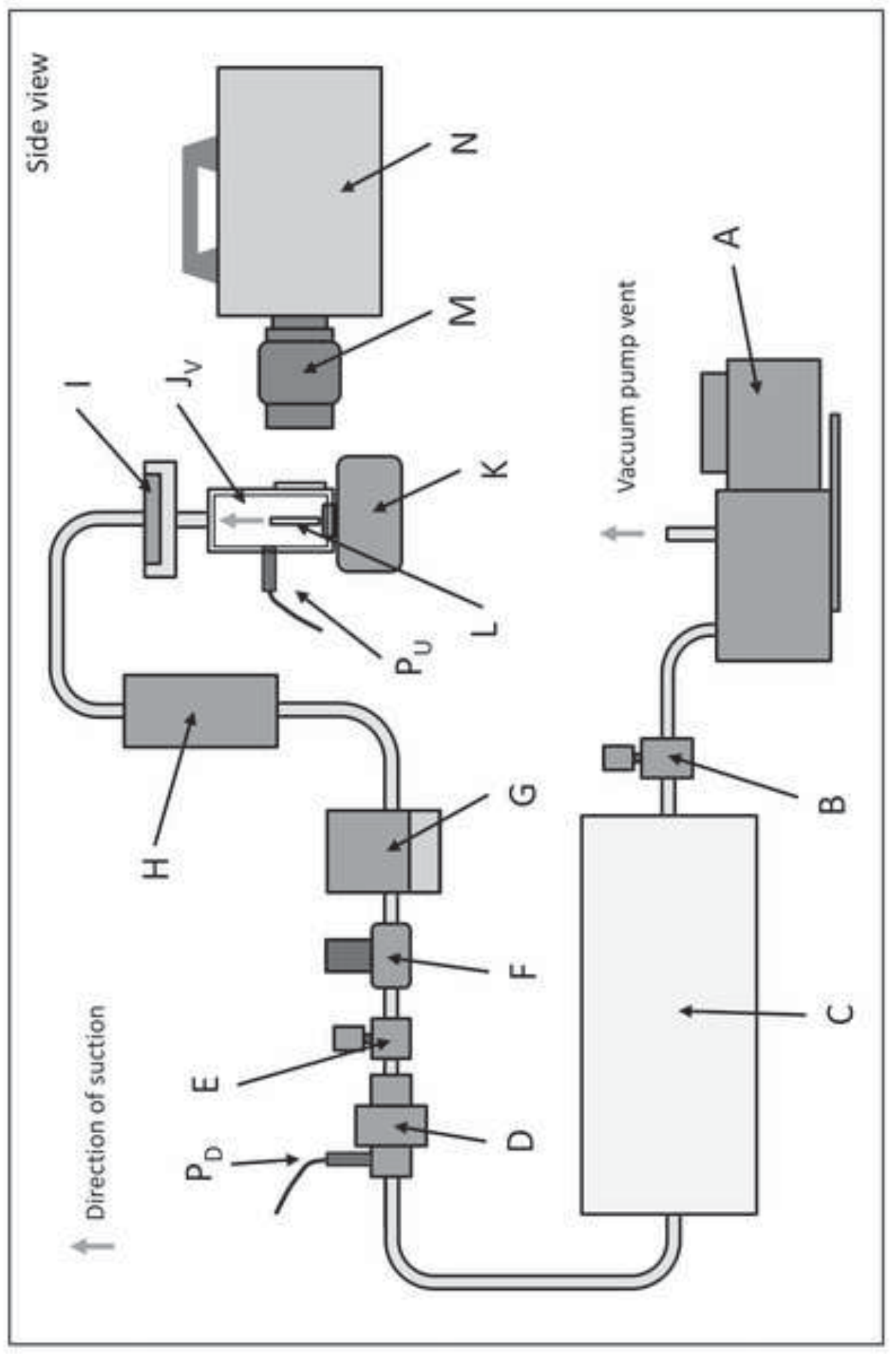

Figure 1 


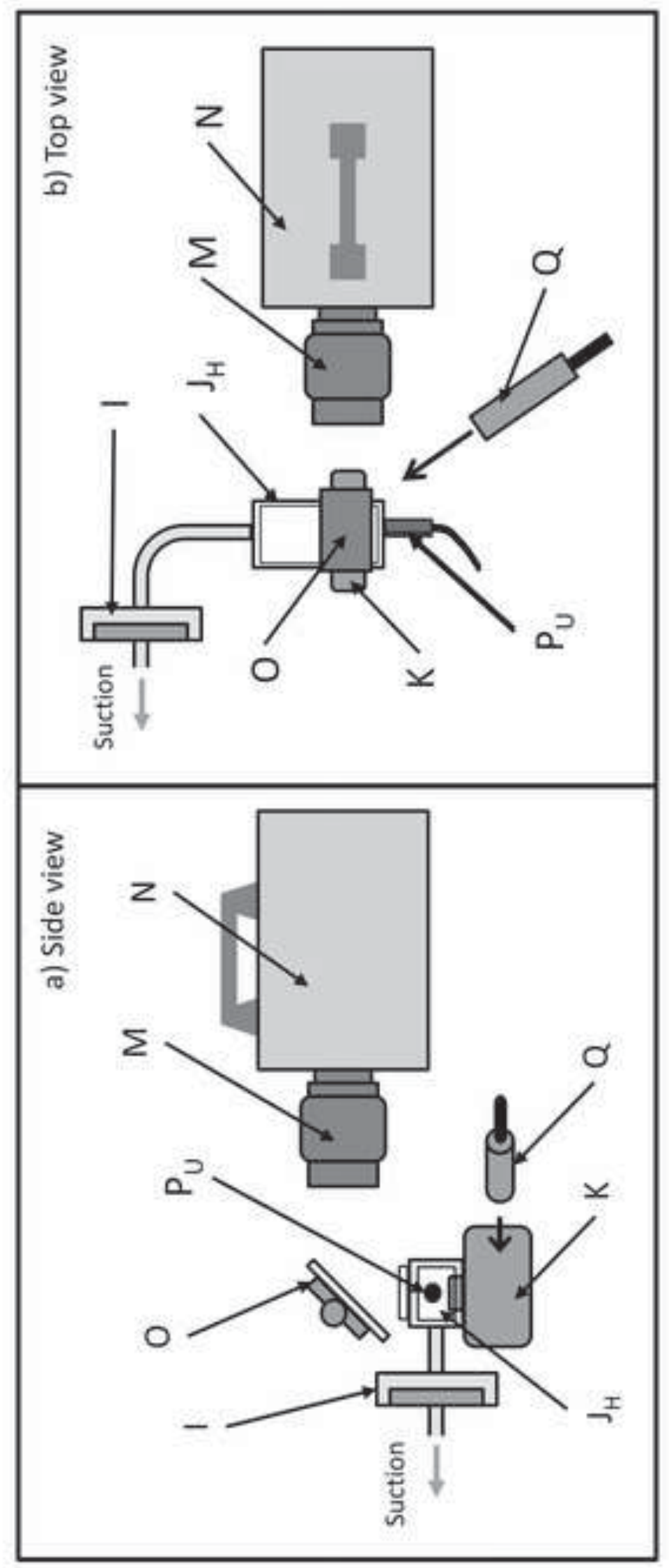

Figure 2 


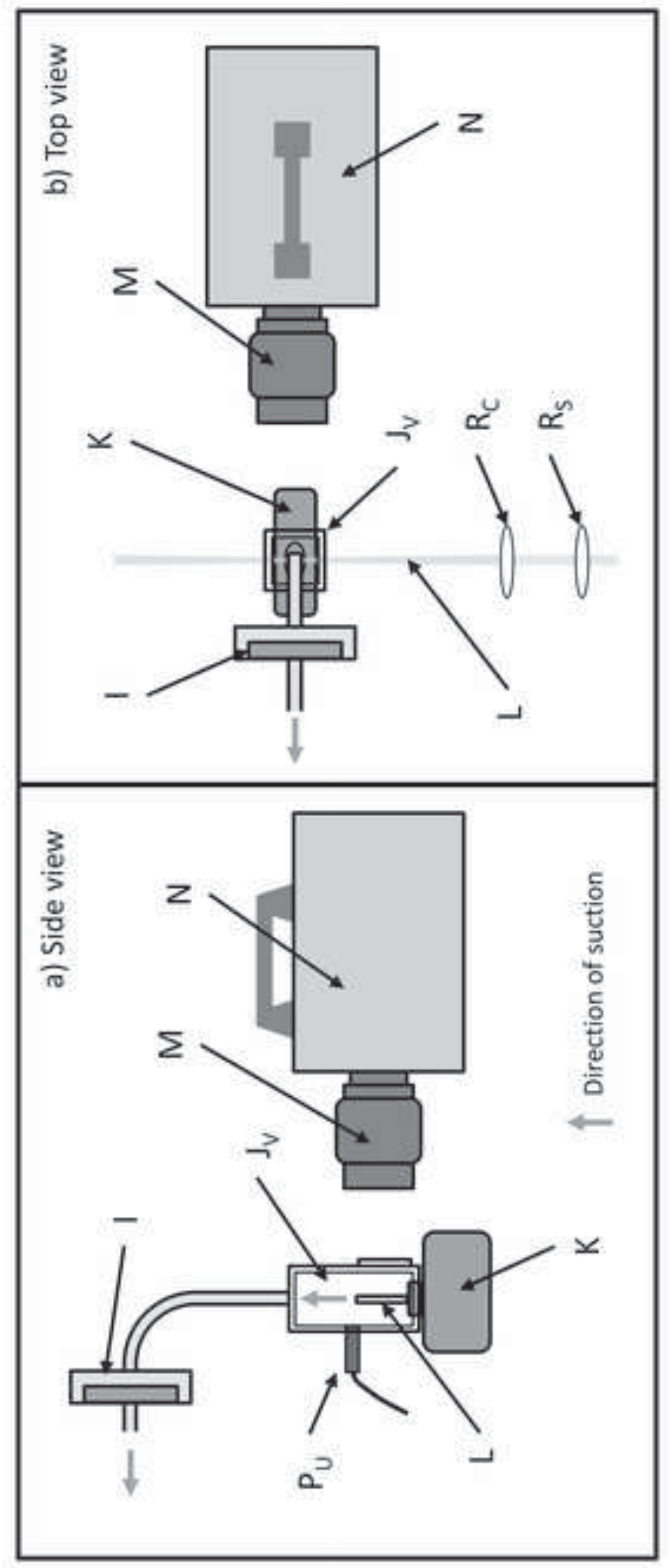

$\frac{0}{0}$
$\frac{0}{5}$
$\frac{0}{4}$

Figure 3 
a)

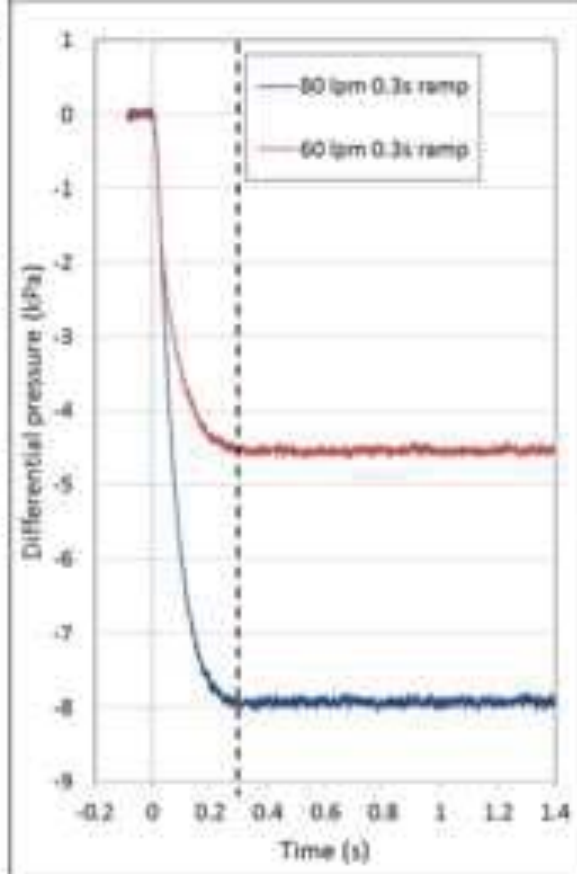

1)t-os

b)

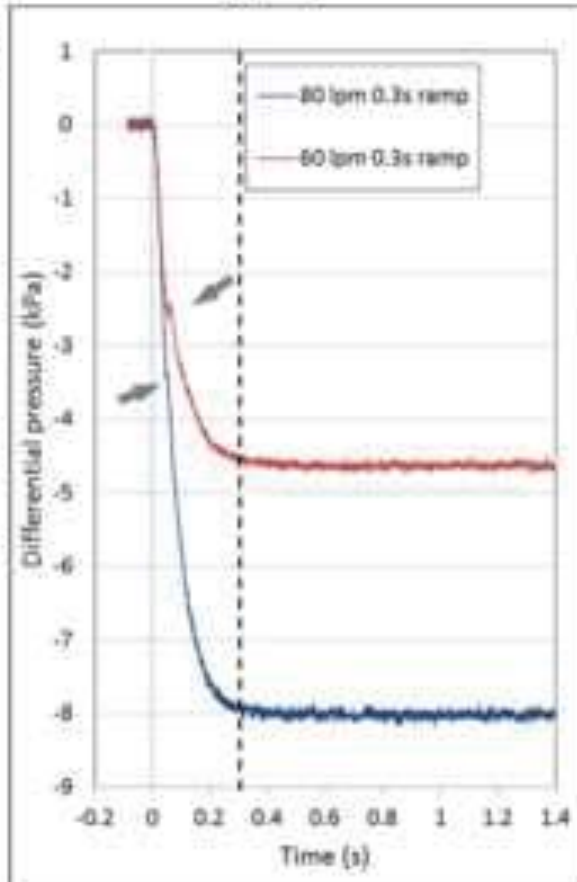

1) $t_{-1}=0.38$

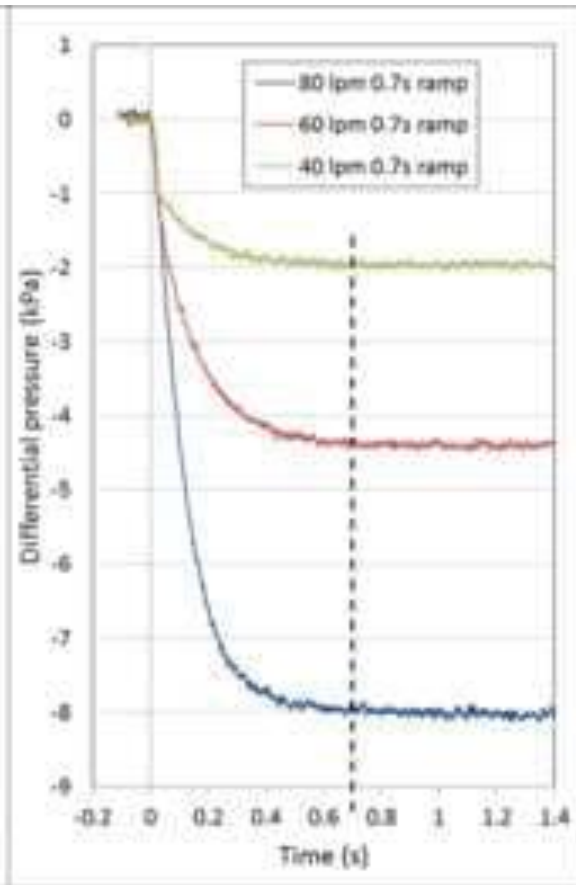

पth $=0.7$

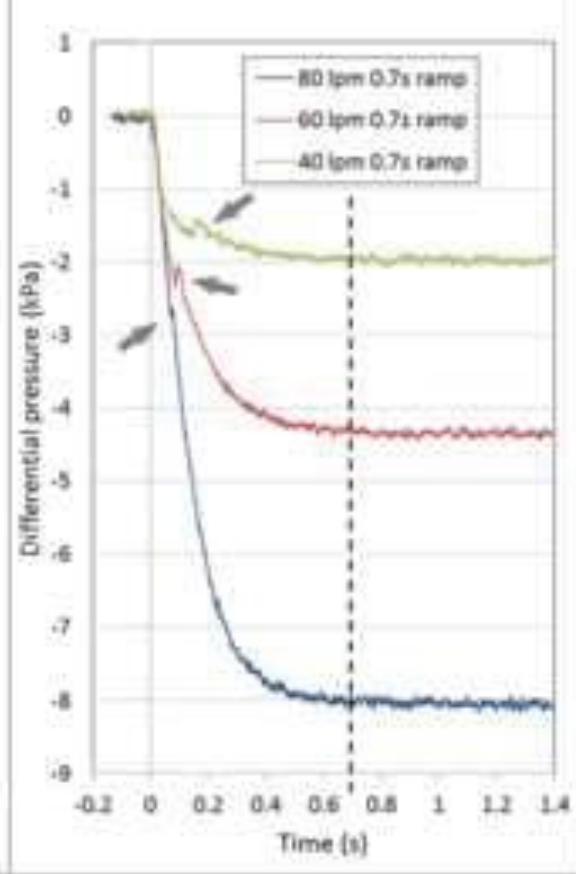

1) $t_{m}=0.7 \mathrm{n}$

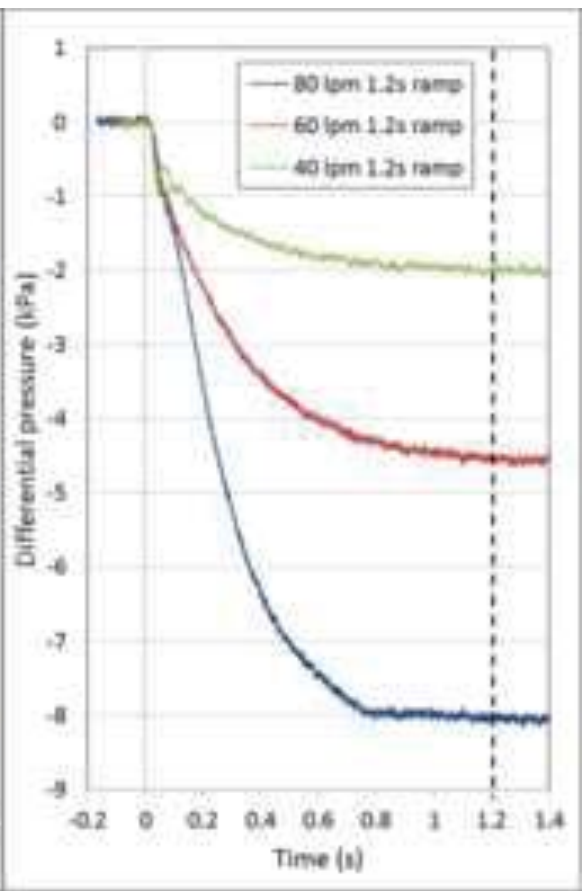

III) $t_{\text {a }}=12$

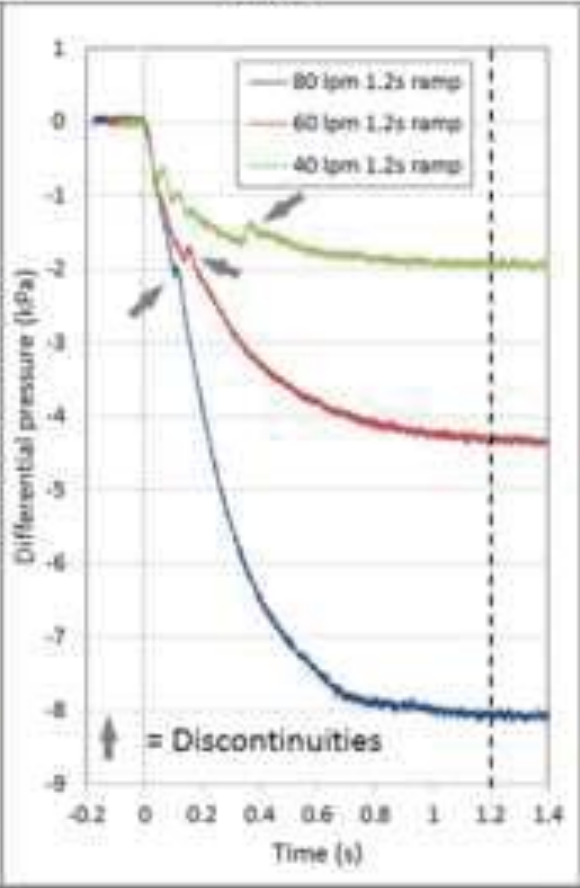

Iili) $t_{w_{0}}=12 \mathrm{~s}$

Figure 4 


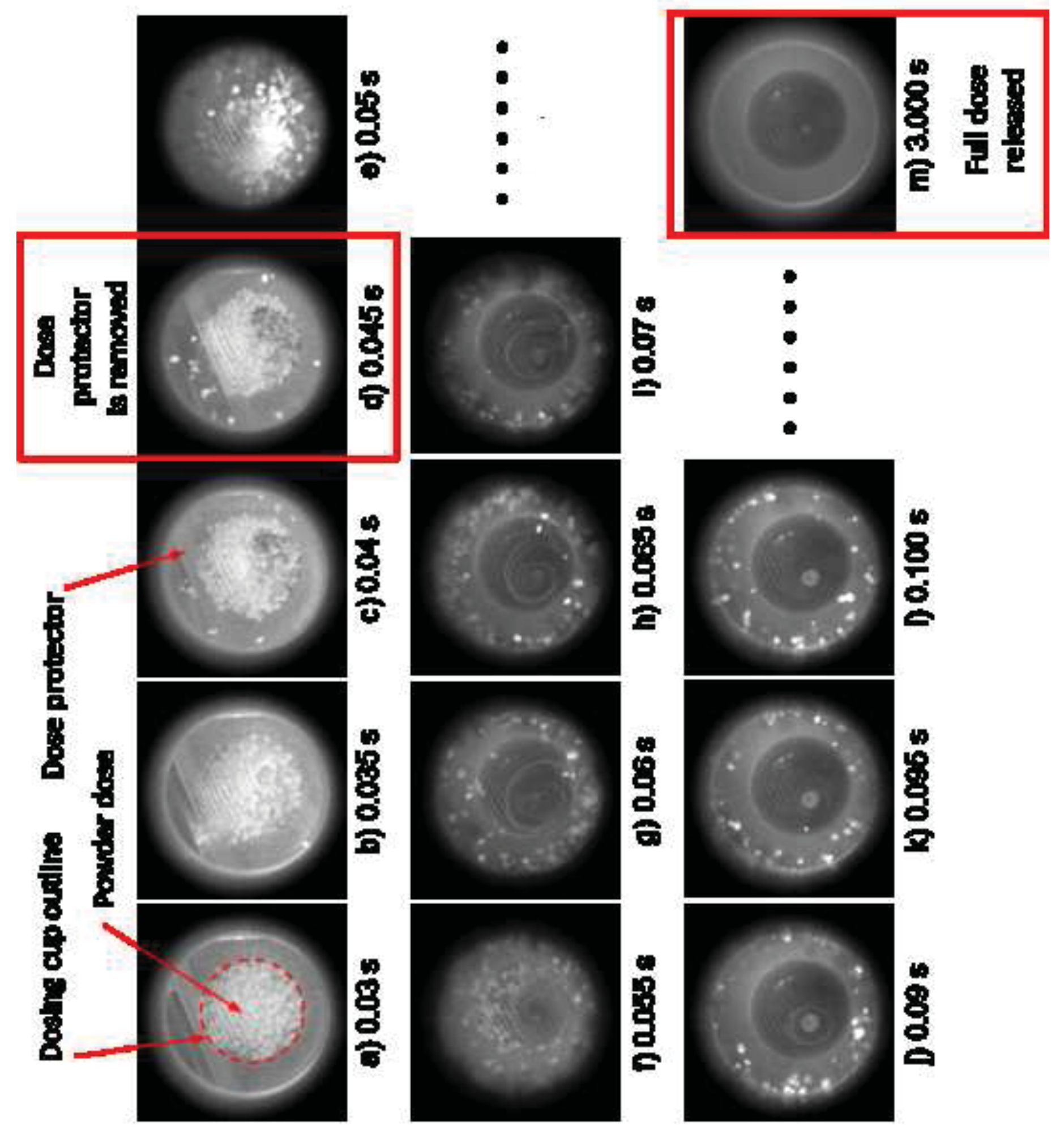

Figure 5 
Figure 6

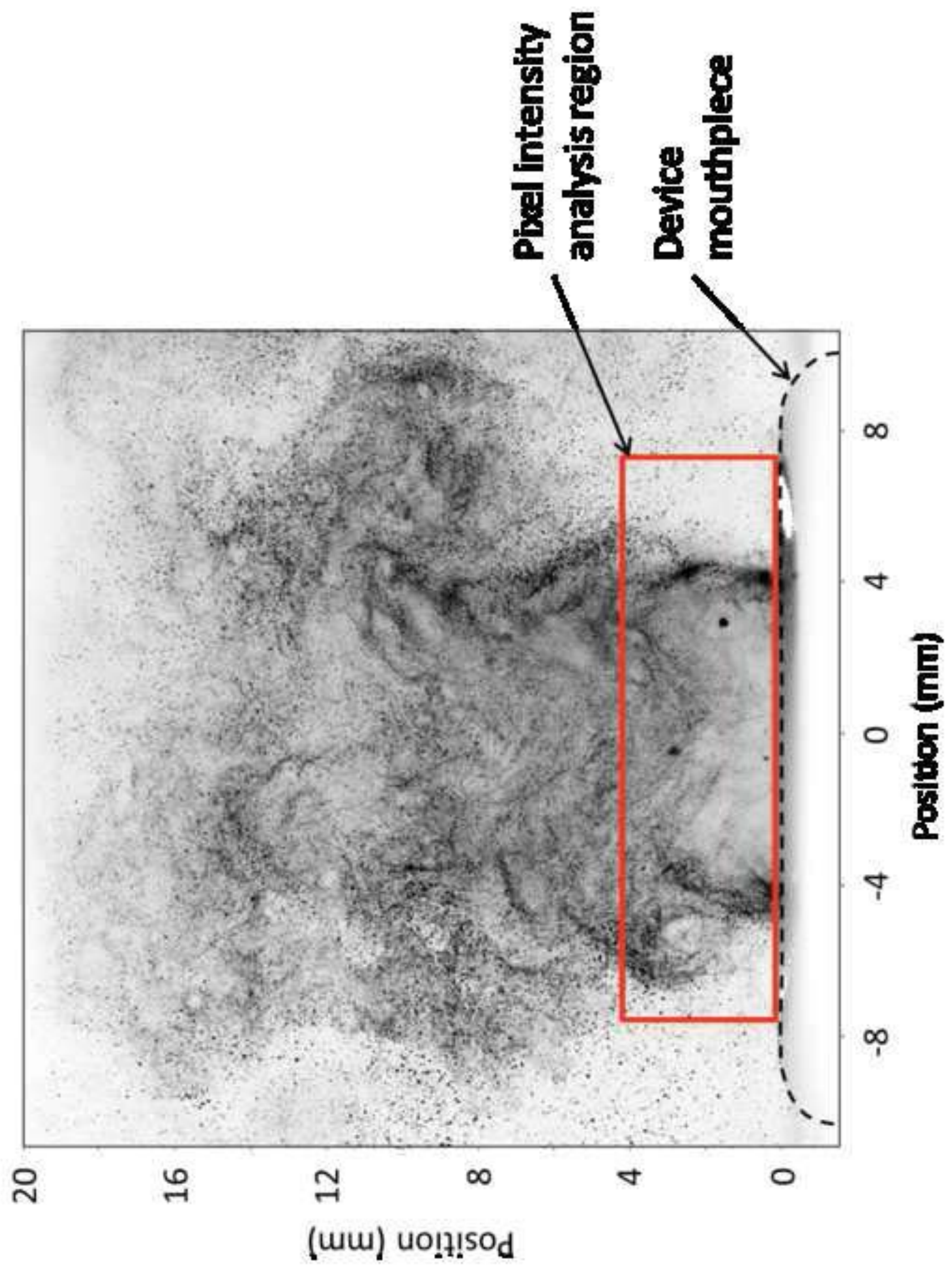

$\frac{0}{0}$
$\frac{0}{5}$
$\frac{0}{4}$ 
Figure 7

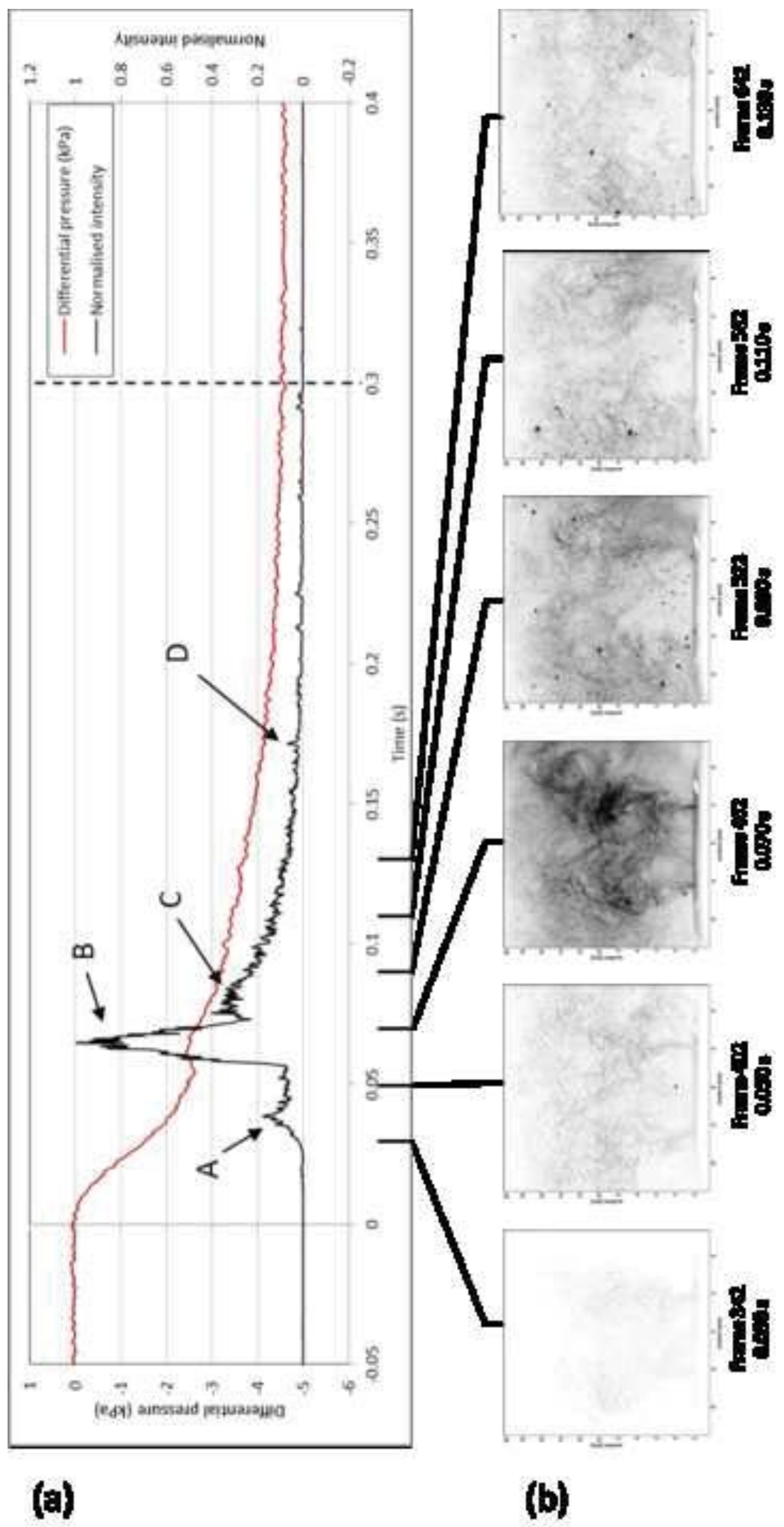

Figure 7 


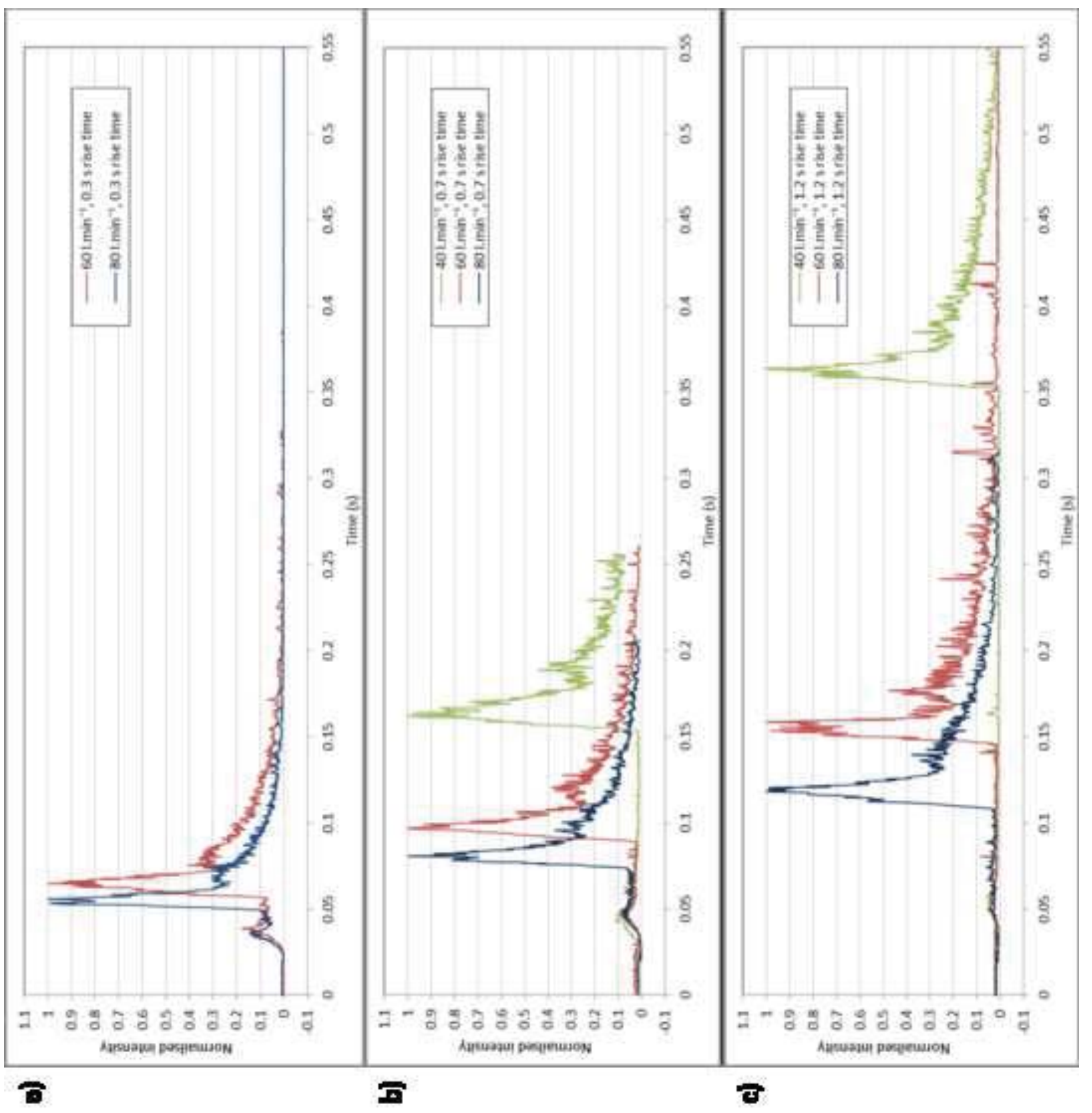

Figure 8 


\section{[s/u] 셔이잇}

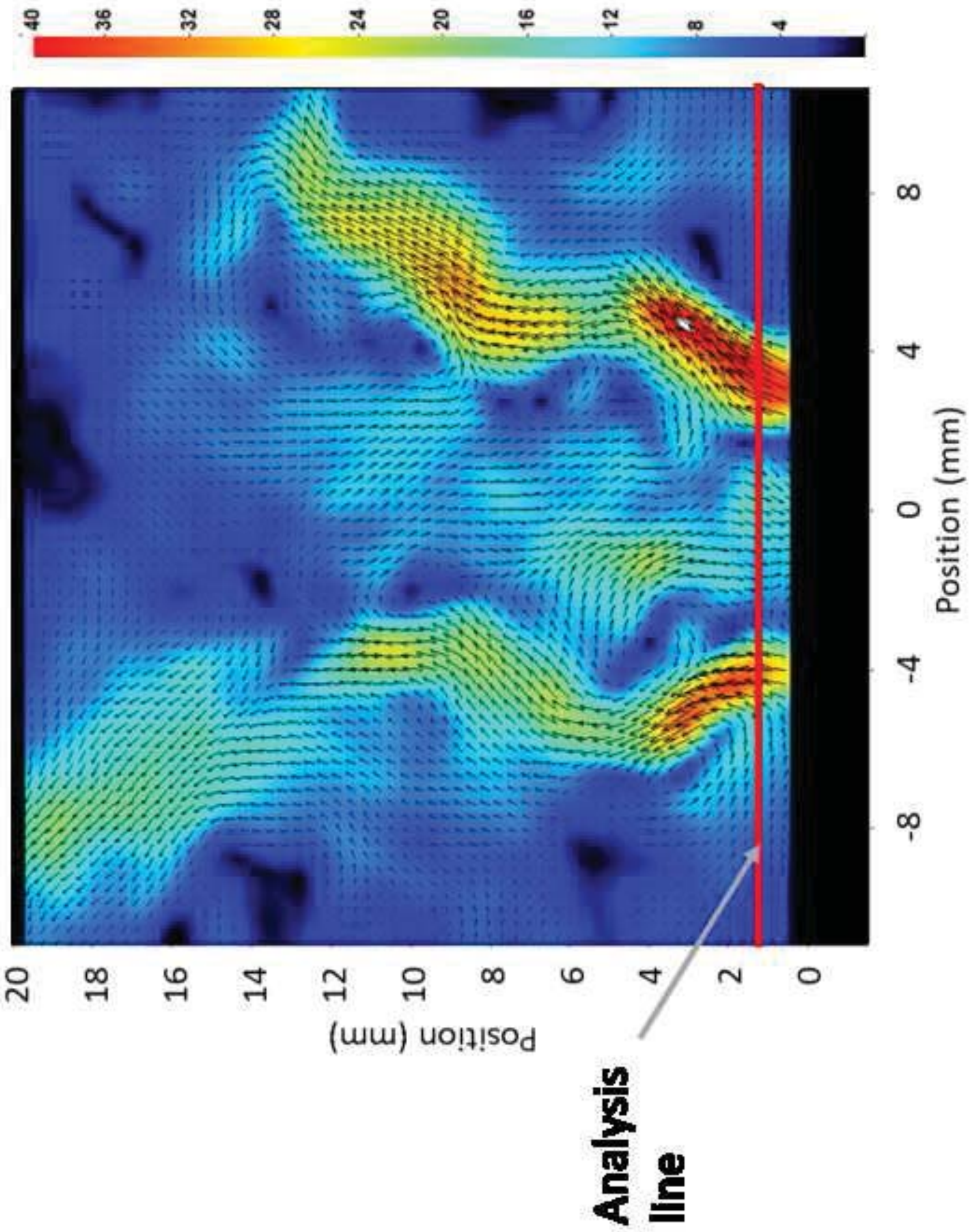

Figure 9 
Figure(s)

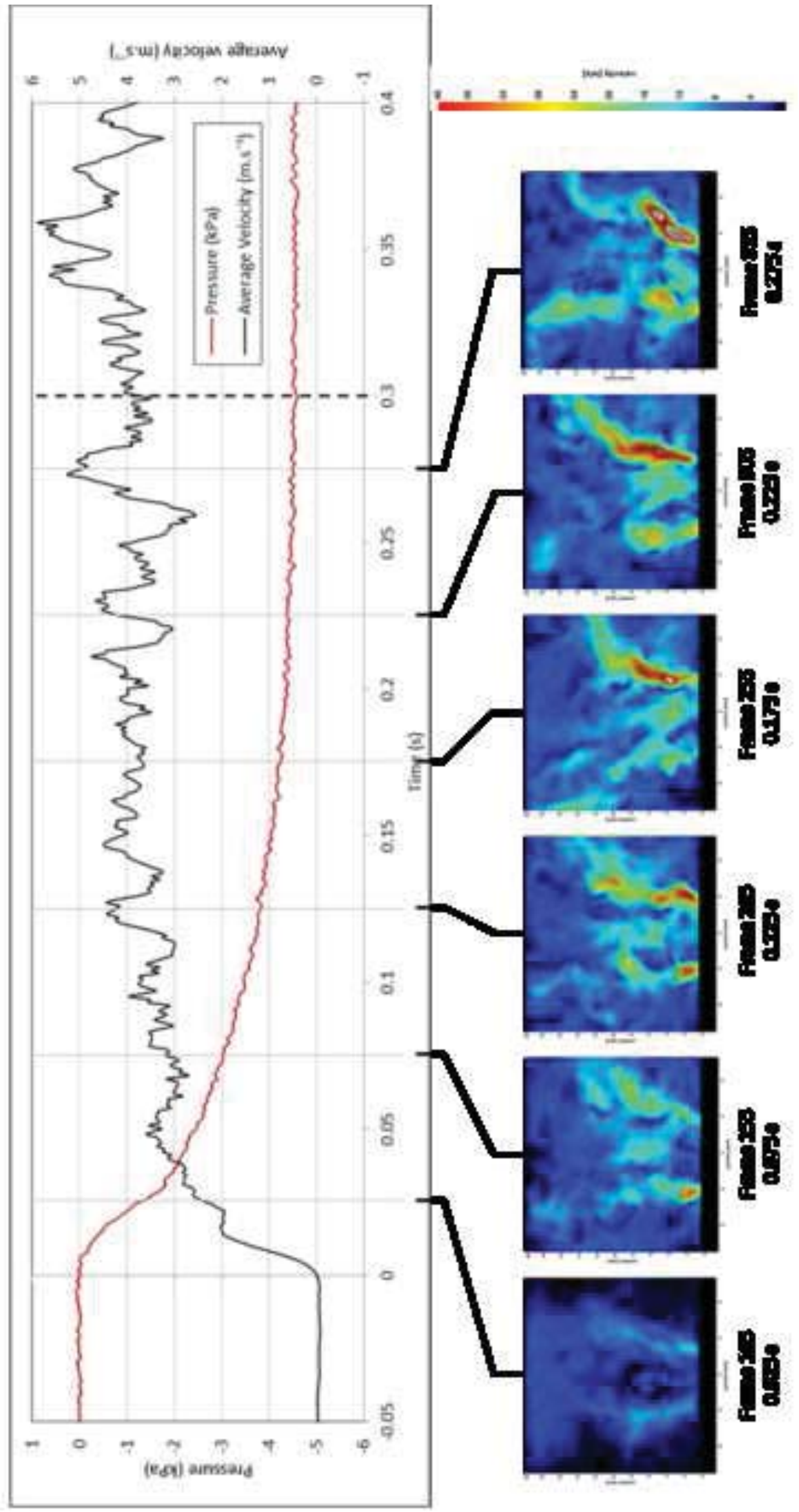

(a)

(b)

Figure 10 